\title{
The politics of publishing: a case study from Nepal.
}

\author{
Pratyoush Onta (Martin Chautari), Ian Harper (University of Edinburgh)
}

In 1994-95 Nepali historian Pratyoush Onta put together a team of four scholars to start a journal about Nepal. They gave it the name Studies in Nepali History and Society (SINHAS) and arranged for it to be published by a new commercial publisher based in Kathmandu, Nepal. First published in 1996, SINHAS is now entering its second decade of publication. The experience of editing SINHAS, doing research on the state of South Asian Studies in India (Onta 2001), and on the state of Nepal Studies in the UK (Onta 2004a, 2004b) have expanded Pratyoush's interests in the general politics of academic knowledge production, distribution and consumption. British anthropologist Ian Harper was interviewed by Onta in relation to this (Harper 2004) and shares similar interests around the politics of knowledge and questions of epistemology and ethics.

Harper and Onta have been jointly thinking about the politics of knowledge generation about Nepal for some time now. In this piece, recorded as a conversation in Kathmandu in 2004, they start with the implications of publishing on Nepal in prestigious journals outside of Nepal. Issues arise over tensions around choosing where to publish, questions of quality and the review process, something about which there should be more empirical and academic discussion. Finally, Pratyoush recounts his experience of setting up, and maintaining SINHAS.

Ian: We've had a number of ongoing discussions. First of all there was your work looking at Nepal specialists in the UK (Onta 2004a, 2004b), and we carried on an aspect of that in a conversation we had looking at responsibilities that we might have to broader Nepali publics when we teach about Nepal in the UK (Harper and Onta, 2004). Now, one of the issues that arises out of this is when we think about our academic enterprise from the perspective of the circulation of the texts we write. There is a tremendous pressure-as I suggested at the public discussion at the Social Science Baha in Kathmandu when your book, Nepal Studies in the UK: Conversations with Practitioners was released-for us UKbased academics to publish in prestigious journals. This is partly related to pressures over the Research Assessment Exercise (RAE), which is a form of audit in the UK looking at research output. Certain journals are valued over other journals, for example, and I wondered how we might begin to think about the implications of this?

Pratyoush: I think it may be useful to think about this in a certain way. Before the RAE became a part of the institutionalized auditing process in the UK, the desire to publish with more prestigious journals was already there. So it wasn't as if there was not already the giving of certain points, and the 
getting of funds linked to this. Publishing in prestigious places was simply a way of getting established within the discipline, so if you had a book with Oxford University Press (OUP) it was better than having a book with an unknown publisher. If you look at the life cycles of some well known researchers, you can see their earlier work published with OUP and then later books are published with relatively unknown publishers as they were in the position in their careers where they no longer needed the backing of such prestige. This is one aspect. Secondly, my work on the UK researchers on Nepal (Onta 2004a, 2004b) revealed a tension in the decision-making process of where to publish. On the part of many of my respondents there was a recognition that their work ought to be available in Nepal. They were concerned with accessibility in two senses. First is physical availability, so that those interested should be able to read it. Second, they considered that those who want to, ought to be able to buy it, so it has to be available at a reasonable price. But on the other hand they are under pressure to publish with prestigious academic publishers and in most cases the furthest they would be willing to go was OUP or the Social Science Press in Delhi. Rarely some may consider Mandala Book Point in Nepal, but Mandala is not recognized as an academic publisher, it doesn't have that brand quality to it and it has very little editorial support. Therefore at a practical level it is understandable why an editor or an author wouldn't want to publish with Mandala because the kind of editorial input you would get from a more established publisher you wouldn't get from Mandala. So there is this tension.

Now I don't have very clear ideas about what needs to happen, but there are some interesting signs like the fact that some publishers now have commissioning editors. I am thinking for example of Himal Books, the publishing wing of the NGO Himal Association. If in the long run, Himal Books establishes itself mostly as a social science publication outlet, then there won't be any justification not to publish in Nepal.

Ian: $\quad$ So is there the potential for Himal to be able to sell its books much more broadly than in South Asia?

Pratyoush: I think that possibility is certainly opening up. There are better ways of sending your books from Kathmandu to India now, than was the case five or ten years ago. But part of the problem of wanting to publish with established academic publishers is a lack of 'maverickness' on the part of researchers. They want to publish with established journals because there is a kind of conservatism associated with the prestige economy. This is about not wanting to take risks because publishing with established publishers means you can be more certain about certain kinds of evaluation mechanisms. If you publish the same stuff with unknown publishers it won't be considered of much quality because those evaluating it wouldn't recognize the brand name. Let's say you were to publish a book with Martin Chautari (an NGO that encourages public discussion and publication in Nepal), they would say 'who is Martin Chautari!' 'Is this a publisher?'- that would be their first question. And you would say, 'yes, it's a publisher based in Kathmandu', and they would ask if it is a commercial or academic publisher, and you would 
say, 'it is an NGO that has gotten into academic publishing'. Now the quality of your work might be very good and the review process of Martin Chautari's own publication unit might also be very rigorous, but those evaluating your work wouldn't give much credit to those mechanisms.

But my own hope is that if it becomes the case that in Nepal that you have a bunch of publishers who say ' $\mathrm{OK}$ we have this quality of publishing, printing and the physical quality of books, and we will provide you with this kind of editorial service, as part of the publication process-we will copyedit the manuscript, and review it etc'-I really hope that more and more researchers associated with Nepal, not just in the UK, but all over the place, will publish their books in Nepal. This just seems to make sense to me. Ideally they should be able to arrange a co-publishing arrangement, where they simultaneously publish somewhere in Europe or the US...

Ian: But why not publish with Oxford University Press (OUP) Delhi, for example?

Pratyoush: Now for OUP Delhi, for any book related to Nepal, the largest market is in Nepal. So it's not as if many copies of such books get sold in India. A few do, but perhaps not more than two or three dozen copies. Given this scenario, it just makes sense for a book published out of the UK or US, to be co-published out of Nepal. The biggest market for that book is being simultaneously addressed.

Ian: But then I suppose there is something about the symbolic capital associated with being with OUP, and their networks of circulation are not inconsiderable.

Pratyoush: Yes, but I hope that our colleagues based elsewhere, people like you and others will begin to actually take risks and say, OK, I am publishing with so-and-so, and although I recognize they don't have the brand name they have the quality so lets try it. Particularly for already well established academics who can take a bit of a risk. For example, two or three books edited and written by UK academics have come out of Delhi in the last two or three years, and there is absolutely no reason why that quality of work shouldn't be done from within Nepal. Without that support then the Nepal publishing industry will always have difficulties competing in the market place.

Ian: One problem, however, is the capacity for smaller Nepal based publishers to both advertise the work more broadly beyond Nepal (say via Amazon) and also to be able to provide these texts to markets outside Nepal.

Pratyoush: That is a challenge that Nepali publishers ought to figure out how to deal with. It's important that individual buyers and universities ought to be able to order and purchase their books on the internet, by credit card.

Ian: Can I turn to questions of academic quality. What about the review process? 
Pratyoush: Academic quality is centrally linked to the review process. Given that there has been an internationalization of research then we end up with an interesting question to think about anthropologically. If you could show that the review process of a publisher in Nepal, any publisher, was more rigorous than the review process of OUP, say, you would end up with a very interesting situation. The publisher in Nepal doesn't have a brand name as recognizable as OUP, but is more accessible to those in Nepal, and serves their concerns, but doesn't serve your evaluation concerns in terms of the expected institutional mechanisms of how books are evaluated and given points in the UK.

Ian: I think that one of the justifications for publishing in particularly prestigious journals is that the rigours of the peer review process are said to create a better quality of research output. Are you suggesting that this is not necessarily the case?

Pratyoush: I am suggesting that we haven't done really good ethnography of the peer review process. There isn't much academic attention given to the peer review process. We might think that we know a lot about what happens, but I don't think we know enough in the social sciences and humanities. I think that there is much more of a concern in what happens in the medical sciences in the peer review process. I've looked for this in the social sciences and there is very little. But also there is a certain amount of mystification to do with this process; is it sufficient just to say that because this has gone through the peer review process this is better than that which hasn't? By and large that might be true, but it doesn't tell us who the peers are, or who is evaluating who. Even in regional studies, peer reviewers are not even necessarily knowledgeable about the concerns of the article. I know for a fact this happens. If any researcher sends an article related to Nepal to international peer reviewed journals, then if that article is sent to an expert on India, a lot of the issues raised will be viewed from the lenses of what is happening in India. If there is an article on the history of child marriage in Nepal, the first thing such a peer reviewer would be tempted to ask is that we've had this child marriage reform movement in India, so why doesn't the writer actually mention that in the article? Now this might be interesting, but not necessary or relevant to Nepal.

Ian: $\quad$ A tendency, then, to lump the history of India and Nepal within the same South Asian regional lens....

Pratyoush: My own sense is this. When you think about how journals select people to do the peer review, it's all by reference. I've reviewed two or three articles for separate journals, in the past five or six years, journals published from different parts of the world, and it was always the case that certain specific individuals who knew me personally, informed the editor that so-and-so in Nepal can review this article. So I reviewed an article on post 1990 politics in Nepal for a journal that comes out from South East Asia. Now, even though it is not my field of research somebody told the editor that I lived in Nepal and by that fact alone am qualified to do a peer review of that article... 
Ian: $\quad$ That's a bit like asking me, by virtue of the fact that I live in Britain, to do a peer review of economics and engineering studies...

Pratyoush: Exactly! Now the only reason I got asked to do that review is that somebody proposed my name to the editor. That's one aspect of the politics of how peer reviewers get selected. Now I realized this several years ago... How do you get asked to review a book for a journal, like for instance the Journal of Asian Studies (JAS)? All kinds of authors and editors send their books to the journal. The journal has different divisions, like 'the world', 'Asia in General', then 'South East Asia', 'South Asia' and so forth. Now a number of years ago, I got asked to review two or three books for JAS because my $\mathrm{PhD}$ supervisor had mentioned my name to somebody who was the then book review editor for South Asia. Otherwise I would never have been contacted by this individual.

Ian: $\quad$ So at one level, then, we don't really know enough about how these circuits (of exchange), networks, and so on, actually work.

Pratyoush: I'll give you an example. Very recently, we received a submission for our journal SINHAS from a Nepali academic. Now I requested the article, and had been pursuing him for many years, and he said OK I've written something for a conference I'll revise it and send it to you. It is on a topic on which none of the current editors have much expertise. So we sent it off to somebody who we thought knew the work of this guy really well. They had worked together in the past. He sent a short review saying that SINHAS publish long discursive articles and this article is not in that category, and moreover it does not add substantively in terms of detail or thematic concerns to the two previous articles written by the author. These two previous articles had been cited in the article being reviewed. Now none of us know the field well enough and so, entirely based on that single person's review, I wrote back to the author saying that 'unfortunately we have to reject your article because our reviewer says it doesn't add substantively to your previous publications'. Now just the other day I received a response from the author stating that the reviewer cannot have read the two other articles that are cited, because this new article is substantively different to the two he had published in the past. Now that puts us in an interesting situation. I was chasing him, so that reflects a desire on the behalf of myself and editorial colleagues to have something published by this guy because he writes quality stuff, we know that. Now we are stuck in a position where we need to verify if our author is correct or our reviewer is correct. The only way we can do that is for me, or one of the editors, to go out and read all three articles. To be fair to the author, we have little choice. Now this recent experience brings up an issue. I had simply assumed that the individual to whom I had turned to review this, would know the work of this author in the past. But it turns out the assumption that drove the review process may be incorrect.

Ian: But there may have been personal or other animosities between them.

Pratyoush: No, that's not the case here. Or I would like to think that is not the case as the reviewer told us that he wishes to work with the person again. 
Both cannot be right at the same time! This is just one example of what is happening in the review process. If we looked at fifteen or twenty such examples, then we might begin to understand the review process much more thoroughly than is the case right now.

Ian: $\quad$ You mentioned SINHAS, so let's talk a little more about this journal. Part of what we want to do is to expose our Anthropology Matters readers to case studies of publishing ventures outside of the EuroAmerican academic sphere. You have a review process then, but how do you go about this?

Pratyoush: Well we've been running for eight or nine years now and we would like to think that the review process is kind of standard. However, others who have wanted to contribute to the journal might not agree with us. Our review process is very simple. In both cases, when we ask for pieces from individuals we know, and when they arrive unsolicited, we simply ask who should review this, and is there anybody in the editorial collective (three or four active individuals presently) who can review this because of previous expertise or exposure to the subject. The attempt is to have it reviewed by at least one member of the editorial collective, and one outside member, just to make sure the process has some quality monitoring mechanisms, not just based on the abilities of the editors. Now, it's not always worked that way. Sometimes it's just been between the editorial collective, in which case we have maintained the semipolicy of identifying ourselves as reviewers. Now when we request that outside reviewers do the work in most cases they don't get identified. When it is members of the editorial collective we tend to identify ourselves. We read and attempt to provide an author the opportunity to revise and resubmit. Now we are not in the position of receiving nine hundred manuscripts for two volumes! Some journals published from the US do get these kinds of loads, and editors will from a quick glance decide whether to go ahead or not, with the review process. We are also in the position of trying to be advocates while at the same time attempting to maintain quality; advocates in the sense that we are requesting people to write in certain kinds of ways for our journal. Now this requires that our review process be rigorous, but at the same time encouraging. We wouldn't just want to say 'your article is worthless', because that would spoil our relationship with that author, or the author community in ways that are quite detrimental to our long term interests; namely, good social science writing on Nepal by both Nepalis and nonNepalis. Moreover, we are also gradually cultivating Nepali authors of a new generation. So that's largely the constraints under which we do the reviews.

Ian: $\quad$ Now there were a number of other possible places where work could be published in Nepal, but your concern was with the quality of social science writing on Nepal?

Pratyoush: At a very personal level the idea of doing such a journal came to me in 1994 in a conversation I had with the owner of Mandala Book Point. Now from that I went back to the US to finish my dissertation and in 1995 I had a conversation with Mary Des Chene and Mark Leichty and 
they were interested in the idea. Then we formed an editorial collective, we had several meetings in two or three different cities in the East coast of the US, where we designed the journal. We launched it from Nepal in 1996. Getting my own work published in journals outside of Nepal would probably have added to my academic worth in other people's eyes, but I didn't do this, because once the journal was started it was important to publish good work in it. One way to do this was to publish good work by the editors themselves, one or two pieces an issue.

Secondly it was an informed response to what was happening in the journal scene in Nepal. There were some very good journals started in the 1970s, particularly two social science journals, Kailash and Contributions to Nepalese Studies. By the late 1980s Kailash had become very irregular, although not quite discontinued.

Ian: Where was Kailash published?

Pratyoush: Kailash was published later from Ratna Pustak Bhandar in Kathmandu, but in the last ten years they have only published two or three volumes. As far as I am concerned it is a journal that is no longer in existence. In its early days Contributions to Nepalese Studies was published from what is now known as the Centre for Nepal and Asian Studies (CNAS). It had a more robust system of quality control in its earlier days than now. The biggest plus point for this journal is its longevity as it's been around for thirty one years. In Nepal many such endeavours don't last that long, so you have to give credit for that and it's never missed an issue.

Ian: And there are some interesting special editions they have published too...

Pratyoush: Yes, that is true. So the possibility of trying to work with such journals was always there, but my sense was that you had to be affiliated with CNAS at Tribhuvan University in Kathmandu and in my case I was not. So it seemed to make sense to start a new thing and see where it would go. Now in retrospect, had I known that the journal would have involved so much hard work I would have seriously thought about not starting it! But having started it, it has now become an interesting venture because the challenge of producing quality is always there. But there is also the extra challenge of not wanting to just give it up... The challenge of keeping it going has become a part of my life, and possibly part of my fellow editors' lives as well, and so we keep going, though it's not very easy.

Ian: We've spoken before of some of the difficulties of trying to institutionalize well meaning endeavours and it's so dependent on the good will of the individuals involved. I guess that institutional support is one of the difficulties you face, is that fair to say?

Pratyoush: Yes, but we need to think about it in somewhat broader terms, like the challenge faced by some other societies some time in the past. Nepal is faced with the situation where in many disciplines and professions, the number of good quality people is very small. Now that is partly a reflection of the fact that these professions are very middle class 
professions, and this phenomena is new in Nepal. In journalism you see the same process at work, where the social base of good quality journalism is very small. And it's even smaller for good quality social science research and therefore for those who want to do good research and maintain a high standard of output, the challenge is to not only invest in your own work, but also in activities that enable that environment. That is to do that work not only for oneself, but for others. And this is where the extra challenge of running the journal enters the scene. For many academics, even in the case of India, because the tradition and social base of doing such work is so much broader, they don't have the added difficulty of being advocates at the same time as running a journal. We run with this double burden.

Ian: I guess there is a parallel when we set up Anthropology Matters, which also has a journal, precisely about becoming advocates for a journal that was specifically set up so that people coming through the process of being disciplined into anthropology, as we phrased it, had an opportunity to write while at the same time trying to maintain a standard. We also had the difficulty of keeping a base, really a rolling base-as these are postgraduates - that is strong enough to keep it supported, and to maintain a certain quality. We also have reviewers, but they tend to be people at the same kind of level—it acts as a peer review-an attempt to create an enabling environment, while not dispensing with quality. And of course the quality is mixed. But one of the things we are lucky to have had grants for was to set it up as a net-based enterprise. That has definitely increased our exposure, and still every week we have people signing up to our e-mail list, so that we are now the largest anthropology e-mail list in Britain.

Pratyoush: What gets sent out on this?

Ian: Well we put out when the journal comes out, when this edition comes out we'll advertise this. Calls for papers, conferences, jobs-we sat down in the early stages and thought about what information would we really have appreciated as postgraduates. So advertising what talks are going on, and this is also dependent on the will of particular individuals to make the effort to circulate this stuff. But it has reached a selfsustaining momentum now. However, I don't think we could have done it without being web-based. Is it possible that SINHAS could go webbased?

Pratyoush: At the moment we are not considering this, as we have left the visibility side of it to our publisher. But we need to think about this more seriously because the quality of it is dependent in part upon its accessibility. If it is not available in major universities in the US, people will turn around and say why publish there when it is not available? We haven't really had much of a response to this question yet. Now web visibility may be one way of moving ahead. Another way is to find out which universities subscribe, and which have stopped, and follow this up and ask if they might reconsider subscribing to it.

Ian: In Edinburgh there are a number of possible budgets that the purchase of such a journal might come under. I've ordered SINHAS through the 
anthropology budget. I suspect that if you just approached libraries, you would not receive much of a response.

Pratyoush: Mark Liechty, one of our editors, works for the University of Illinois in Chicago. He went to his library and they told him they didn't have the budget to subscribe to SINHAS. It was not a priority area for faculty.

Ian: What is your print run like and where does it go?

Pratyoush: In the beginning the print run was 500-600. The first issue was sold out, and our publisher decided to reprint it. It was sold out through both subscription, and from his shop and other outlets. Initially the subscription base was larger than what it is now. Now volume 1, issue 2 was a thematic issue on Nepal's development scene. Feedback from the publisher then was that this issue didn't do so well as it was very thematically specialized. As such it didn't draw the attention of academics interested in more general issues.

Ian: Perhaps, but the development discourse is such an over-arching phenomena in Nepal that it should have had more general relevance...

Pratyoush: Well this was 1996, and at this time the links between development and anthropological concerns was much less understood than is the case today. Not just the Nepal scene, but more generally in anthropology. Development is now much more of a thematic concern for the discipline. I am happy to say that in the long run, that issue got sold out completely. The print-run of current issues is still between 500-600 copies.

Ian: Development is certainly one of the growing sub-disciplinary areas within anthropology. Where is SINHAS available in Nepal?

Pratyoush: It is available in a few libraries in Kathmandu, both within the Tribhuvan University system and outside. I sent copies to the Pritvi Narayan Campus in Pokhara in the early days of the journal, but when I visited earlier this year I discovered that the copies I had sent were no longer there. The copies were never registered in the system, and so they could not be found in the library. Now I don't want to spend my own money, buy up the existing issues and send them there again! I might ask the publisher to do a work of charity... It is a problem as their library is facing severe budget constraints. From this perspective our journal may be seen as a very specialized activity, for masters and $\mathrm{PhD}$ level students, and they don't have a scheme for PhDs in the social sciences yet.

Ian: It seems to me that SINHAS is very much dependent on your personal drive and that of the editorial team.

Pratyoush: No doubt about that. Here and elsewhere. In the UK, it's not as if personal drive is not important, that and the quality of the editors and their commitment. Journals have life cycles which under some editors develop their quality, and under others the journal quality can decline. Everywhere there are a whole set of parameters that determines this quality. The difference is in the mix between institutional support-in terms of peer review activity, copy editing, publishing, marketing, financial resources - and personal drive. The institutional parameters are 
more dominant in the UK, whereas in Nepal the personal drive element is much more important.

Ian: $\quad$ So in conclusion, to understand our academic enterprise better, we need to pay more attention to the geography of publishing and its politics; the view, if you like, of the world from the perspective of the circulation of our texts tells us much about the political economy of academia. We should be more aware of the implications of where we publish for the diversity of publication ventures; what we do can undermine that diversity, or, strengthen it. Thank you very much for your time.

\section{References}

Harper, I. 2004. Interview. In Nepal studies in the UK: conversation with practitioners (ed) P. Onta, Kathmandu: Martin Chautari.

Harper, I. \& Onta, P. 2004. Teaching the canon? reflections on anthropology's responsibilities. In Teaching rites and wrongs: universities and the making of anthropologists (eds) D. Mills \& M. Harris, Birmingham: Centre for Learning and Teaching Sociology, Anthropology and Politics (C-SAP).

Onta, P. 2001. Regional area studies in South Asia: dark days ahead. Nepali Journal of Contemporary Studies 1 (2), 60-89.

Onta, P. 2004a. Introduction. In Nepal studies in the UK: conversation with practitioners (ed) P. Onta, Kathmandu: Martin Chautari.

Onta, P. 2004b. Nepal studies in the UK: conversation with practitioners. Kathmandu: Martin Chautari.

\section{About the publishers}

For more information about the publishers mentioned in this article visit the following web sites:

CNAS: http://www.tribhuvan-university.edu.np/research.php\#CNAS

Martin Chautari: http://www.martinchautari.org.np/

Mandala Book Point: http://www.mandalabookpoint.com/

Himal Books: http://www.himalassociation.org/himalbooks/

Ratna Pusthak Bhandar: (No web address) P.O. Box 98, Kathmandu, Nepal.

\section{About the authors}

Pratyoush Onta is currently doing research on media and academia in Nepal. Ian Harper lectures in social anthropology at the University of Edinburgh. 